\title{
Gênero e etnicidade na literatura de autoria feminina
}

\author{
Maria do Rosário Alves Pereira \\ Doutoranda em Literatura Brasileira / UFMG
}

\begin{abstract}
RESUMO
O objetivo deste trabalho ${ }^{1}$ é tecer algumas considerações sobre poemas e contos de escritoras negras contemporâneas a fim de demonstrar o quanto o ponto de vista interno da autoria influencia na voz do eu lírico e nos perfis de personagens construídos. As escritoras selecionadas para este artigo são Cristiane Sobral, Lia Vieira, Conceição Evaristo e Esmeralda Ribeiro, que abordam em sua literatura questões como memória ancestral e papéis sociais exercidos e aceitos (ou não) pela mulher negra na contemporaneidade.
\end{abstract}

\section{PALAVRAS-CHAVE}

Literatura de autoria feminina, etnicidade, escritoras contemporâneas

Como se dá a representação da mulher negra na literatura brasileira contemporânea? Certamente que essa indagação não pressupõe uma única ou uma simples resposta. Se se pensa nessa representação a partir de um olhar fora da problemática, ou seja, figurações a partir de um discurso patriarcal, tradicional, encontram-se muitas mulheres negras estereotipadas, excessivamente sexualizadas, com matizes carregados de perversão, como a Rita Baiana de $O$ cortiço, de Aluísio Azevedo, por exemplo. No entanto, ao se deslocar a ótica de fora para dentro da questão, isto é, representações que partem de uma autoria negra feminina que expõe, de modo mais direto ou não, sua escrevivência - para utilizar o conhecido conceito de Conceição Evaristo - ressignificada sob a pena literária, o eu-lírico, na poesia, e as personagens, na

\footnotetext{
${ }^{1}$ Este trabalho é uma versão revista e ampliada do texto apresentado no III Colóquio/I Encontro Nacional Mulheres em Letras, em maio de 2011.
} 
prosa, seguramente serão bem diversos daqueles calcados numa visão essencialista, na doxa vigente.

À luz dessas considerações é que serão abordados neste artigo a poesia de Cristiane Sobral e os contos de Lia Vieira, Conceição Evaristo e Esmeralda Ribeiro, em uma leitura panorâmica que não pretende, de modo algum, esgotar as possibilidades interpretativas de tais textos. O recorte se deve à aproximação existente entre a literatura dessas escritoras, que retrata, em alguma medida, a importância da memória, tanto a coletiva quanto a individual, e da ancestralidade como modo de preservação e perpetuação de uma cultura.

A escritora Cristiane Sobral é um tanto quanto contundente na sua forma de expressão. Não vou mais lavar os pratos (2010), sua mais recente publicação, apresenta poemas em que dados da história negra no Brasil são lidos sob um viés mais crítico, como por exemplo no texto de abertura que dá nome à coletânea:

Não vou mais lavar os pratos

Nem vou limpar a poeira dos móveis

Sinto muito. Comecei a ler. ${ }^{2}(.$.

Não lavo mais os pratos

Quero travessas de prata, cozinhas de luxo

E jóias de ouro.

Legítimas

Está decretada a lei áurea. ${ }^{3}$

O significante "não”, no primeiro excerto, assume o seu "significado" mais pungente: em uma primeira leitura, poderia se pensar em um sujeito lírico que repudia o lugar comumente atribuído na sociedade àquele considerado subalterno, tal como as empregadas domésticas ou mesmo as donas de casa que permanecem confinadas em seus lares a realizar funções ditas tipicamente “do lar”. No entanto, é possível aprofundar a leitura e atribuir a negação a toda e qualquer função ou papel tido como “menor” ou “desclassificatório” em uma sociedade tão presa às aparências. A ironia do "sinto muito. Comecei a ler" aponta novas possibilidades, traduzidas na sequência do poema, por "mãos bem mais macias que antes”, e que agora, ao invés de simplesmente se desgastarem com o trabalho físico, folheiam livros, numa alusão à importância que o trabalho intelectual pode ter como promotor efetivo de mudança para esse sujeito, e os

\footnotetext{
${ }^{2}$ SOBRAL. Não vou mais lavar os pratos, p. 23.

${ }^{3}$ SOBRAL. Não vou mais lavar os pratos, p. 25.
} 
olhos, rasos d'água, querem entender o porquê de se manter, sem questionamentos, a ordem hegemônica.

Na última estrofe, o eu poético nos lembra de que, se a Abolição ocorrida em 1888 foi um ato quase meramente político, uma vez que não alterou substancialmente a condição socioeconômica dos negros, essa parcela da população ainda continua, e cada vez em maior escala, à procura de novas formas de inserção social, em busca da sua própria lei áurea, em busca de direitos iguais à parcela "branca” da sociedade.

A escravidão, a diáspora, a herança cultural africana e a assunção da identidade negra são marcas impressas no corpo e na escrita dos afrodescendentes. "Se você me quiser, vai ser com o cabelo trançado", diz o eu lírico do poema "Sonho de consumo". Ou seja: inclusive para haver um encontro amoroso com um outro, esse encontro de fato só existe se a identidade do sujeito que se quer negro for respeitada, parece dizer o texto. E mais: se a personalidade feminina, por vezes multifacetada, também o for. "Se você realmente me quiser, ouse digerir a contradição”, sentencia esse eu lírico.

Aliás, a condição feminina parece ser mesmo um dos motes propulsores da escrita de Sobral, a se refletir em novos painéis para a mulher na atualidade, diferentes daqueles tradicionalmente estabelecidos, como se lê no poema “Abrúptero”:

Quem disse que são infelizes as mulheres inférteis?

Quem disse que são felizes as mulheres com as suas mamadeiras?

É preciso ter muito peito para não parir e não parar

É preciso ter muito peito para enfrentar as surpresas da existência. ${ }^{4}$

A primeira estrofe do poema aponta um eu enunciador que questiona o status quo vigente, os valores logo e falocêntricos. Por que à mulher deve caber essencialmente o destino da maternidade? Na literatura tradicional, são recorrentes os textos que descrevem a figura das chamadas solteironas, em geral como mal amadas e infelizes, mulheres de triste sina, por assim dizer. E a elas, quase sempre, o estereótipo da clausura e do confinamento, das palavras e gestos nunca ditos, do amor nunca expressado. Esse estereótipo, certamente reforçado por uma mentalidade machista, ainda perdura, sutilmente. Mas "não é preciso crer na falta como um defeito”, conforme nos alerta o poema de Cristiane. Ao contrário: o “abrupto” - e ao longo do texto a escritora brinca com o significante, criando as formas "abrúptero" e "abrútero", ambas remetendo a útero que, por sua vez, remonta a gestação, a vida, nascedouro, não de um feto exatamente, mas de outras formas de vida, no sentido conotativo -, aquilo que

\footnotetext{
${ }^{4}$ SOBRAL. Não vou mais lavar os pratos, p. 42.
} 
ocorre de maneira súbita pode surpreender positivamente, trazendo novas formas de felicidade. Além disso, quase sempre o que ocorre na realidade destoa dos finais hollywoodianos, excessivamente glamourizados e romantizados. $O$ tom quase panfletário, de um discurso proferido em praça pública, certamente lembra o "Abaixo os puristas!”, de “Os sapos”, de Manuel Bandeira, suplementando, no sentido derridiano, a chamada literatura canônica.
Abaixo os inacreditáveis roteiros com final feliz
Vaias amplificadas para a tendência latina aos melodramas...
Viva a coragem de encarar os próprios problemas!
Algumas dores jamais serão resolvidas ${ }^{5}$

Saliente-se que esse tom declamatório aparece pelo menos em mais dois poemas desse livro, "Declaração” - “Abaixo as paixões infinitamente provisórias!”6 - e "Revolução", texto este que incita o público leitor feminino a deixar o lugar estático de “boneca”, de símbolo sexual, de carne para o consumo masculino.

Desse modo, a mulher que não se rende aos valores impostos pela sociedade, que adota posturas diferentes, pode ser vista como estranha ou "estrangeira" dentro de seu próprio lar, ambiente de trabalho, roda de amigos, e, ao mesmo tempo, e de modo ambíguo, deixar de ser uma estranha para si mesma, como sinaliza o poema "Estrangeira”, publicado em Cadernos Negros 23: "Resolvo conjugar o Eu em voz alta./Sem papai, igreja, nem sistema.”

E, se o padrão de beleza da atualidade ainda continua sendo o europeu, não devemos nos esquecer do que de fato somos, conforme expresso no poema "Cuidado", um dos mais significativos no que diz respeito à identidade negra. Valores deturpados muitas vezes são introjetados pelas propagandas e por tudo um discurso da moda e da mídia que tentam convencer o espectador/consumidor, sobretudo feminino, de que magreza, cabelo liso, louro e pele clara são sinônimo de beleza:

De repente

Sonhamos com toalhas amarradas na cabeça oca

Num passe de mágica

Aceitamos o codinome pixaim e o sobrenome bombril ${ }^{7}$

\footnotetext{
${ }^{5}$ SOBRAL. Não vou mais lavar os pratos, p. 42.

${ }^{6}$ SOBRAL. Não vou mais lavar os pratos, p. 43.

${ }^{7}$ SOBRAL. Não vou mais lavar os pratos, p. 74.
} 
E o negro, bombardeado por imagens e informações a dizer-lhe o tempo todo que suas características fenotípicas estão fora de moda, não correspondem ao ideal estético dominante, vê sua autoimagem esfacelada, e perde sua consciência crítica:

Começamos a achar que o problema está na nossa cabeça preta

Nunca no olhar do outro

Nunca no deboche do outro

Nunca no sorriso de lado ${ }^{8}$

No caso da escritora carioca Lia Vieira, ainda que neste trabalho objetive-se a leitura especificamente de um conto seu, cabe uma breve consideração sobre sua poesia apresentada nos Cadernos Negros, em que se nota uma ressignificação do vocabulário relacionado tanto ao tema negro como ao tema feminino, conforme o poema a seguir:

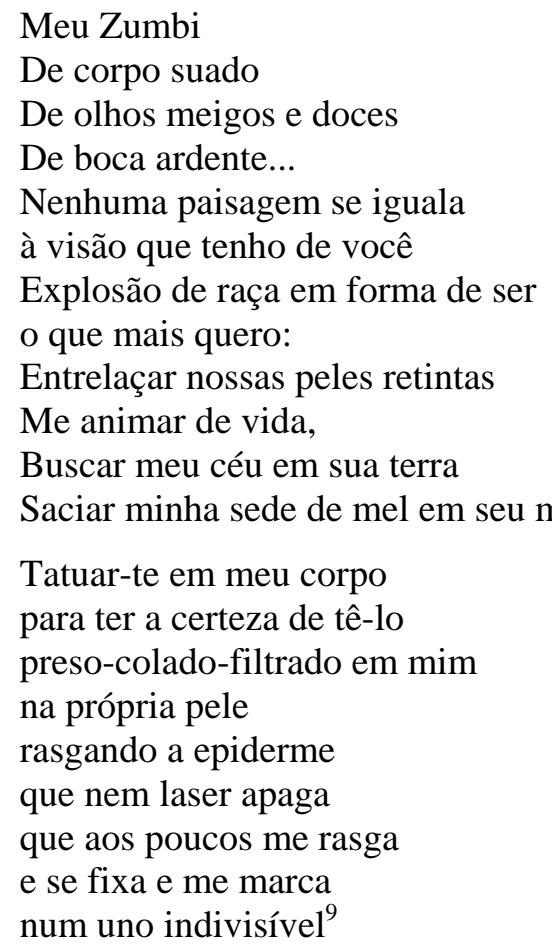

A autora reconstrói a imagem de Zumbi, apropriando-se do herói épico para reconstruí-lo sob o ponto de vista de um eu lírico feminino e desejante, em um movimento de afirmação. Zumbi pode ser lido como uma metáfora que se refere a um amante concreto. De herói da história negra, no poema, ele passa a ser representante da liberdade do prazer feminino, e em seu corpo deixa impressa a força dos antepassados

\footnotetext{
${ }^{8}$ SOBRAL. Não vou mais lavar os pratos, p. 75.

${ }^{9}$ VIEIRA. Meu Zumbi, p. 58.
} 
como uma espécie de inscrição, de tatuagem ali presente. O guerreiro virou amante, e o erotismo converte-se numa forma de libertação dos valores patriarcais instituídos.

Tratando agora da prosa, em "Rosa da farinha”, conto publicado nos Cadernos Negros 22, o que se narra é uma história de descendências. O enredo é contado em primeira pessoa pela neta de uma protagonista forte e lutadora, Dona Rosa, ou a "Rosa da farinha”, tendo recebido esse apelido devido às funções que exercia na produção do alimento. É descrita como sendo dotada de uma “autoridade natural”, porte um tanto quanto imponente, e olhos que deixavam revelar sentimentos de "tristeza e dor, alegria e beleza, coragem e esperança”. Mantenedora junto com o marido da Fazenda Campos Novos, ela se destaca por ser uma espécie de conselheira na comunidade:

Era muito simples o que ela ensinava. Dizia que somos maiores do que pensamos e que a resistência é o caminho para romper os grilhões. Mas o que mais impressionava não era a doutrina, e sim a mulher, sua benevolência, a grandeza de alma, a determinação. ${ }^{10}$

A origem daquela comunidade remontava ao tempo da escravidão. E o fantasma dos maus-tratos, da violência, do jugo senhorial ainda assombrava a muitos.

Vó Rosa é também uma figura lendária: ao longo de sua vida, torna-se conhecida sobretudo por enfrentar com coragem os desmandos da polícia e dos grileiros de terras. E o “o sistema comum da posse da terra, baseado na descendência dos antigos, seus usos e costumes”, prevalece ao longo do tempo como resultado da luta de uma vida inteira pelo fortalecimento daquela comunidade.

Outro ponto interessante é que Rosa da Farinha, como guardiã da memória de um povo, assemelha-se aos griots africanos, contadores de histórias responsáveis pela perpetuação da cultura. A personagem de Lia Vieira conta histórias da escravidão, de plantas medicinais, da culinária - a farinha, o inhame, o beiju, a tapioca: heranças africanas que a neta também pretende resguardar:

Um dia hei de ter tempo de tomar para mim todo o tempo que me apetecer, e, neste dia, todas as histórias, vivências e pressentidos de Vó Rosa e dos parentes vão incorporar-se à minha vida. Tal é o poder da herança-memória. (...) É dessa fusão de tempos perdidos que desejo fazer o meu tempo; essa colheita de tempos fugazes. Possa eu viver ainda, porque há em mim tanto que não foi visto, concedam-me a estação das contemplações e mesmo se os tratores apagarem a terra ou as divisas do território, peço a sobrevivência remanescente da

\footnotetext{
${ }^{10}$ VIEIRA. Rosa da farinha.
} 
identidade de nós outros, pois será assim meu corpo, decomposto e renascido. ${ }^{11}$

O conto termina aí, conclamando à sobrevivência da identidade de um povo.

Em "Duzu-Querença”, de Conceição Evaristo, há uma subversão da representação canônica e por vezes um tanto quanto glamourizada da prostituta. Duzu chega ainda menina em um bordel, levada pelo pai, a quem Dona Esmeraldina havia feito a promessa de que a menina poderia estudar na cidade grande. $O$ tema da esperança perpassa todo o texto, já a partir daí: não é de má-fé que a menina é separada da família, indo residir em outra cidade. O pai alimentava a ideia de que a garota ali pudesse ter um destino promissor. Essa expectativa não se concretiza, ainda que a menina fosse “caprichosa” e tivesse “cabeça para leitura”. Após trabalhar como empregada doméstica, Duzu acaba se tornando prostituta.

A violência acompanha a narrativa desde o princípio:

Duzu lambeu os dedos gordurosos de comida, aproveitando os últimos bagos de arroz que tinham ficado presos debaixo de suas unhas sujas. Um homem passou e olhou para a mendiga, com uma expressão de asco. Ela devolveu um olhar de zombaria. ${ }^{12}$

É nesse lugar de indigência social que Duzu se dá a conhecer ao leitor, no primeiro parágrafo do conto. A narrativa, em terceira pessoa, utiliza o artifício do flashback, numa narrativa de formação, poderíamos assim dizer. ${ }^{13}$ Pelas reminiscências da protagonista negra, o leitor conhece sua história - e aqui já se percebe que o lugar secundário ocupado pelas personagens de cor na literatura canônica cede lugar para o protagonismo na literatura afrodescendente.

A narrativa é permeada por um tom lírico, a bem dizer, um certo "brutalismo poético” já apontado largamente pela crítica na obra de Conceição Evaristo. Trata-se de uma linguagem concisa, mas densa de significados. Mesmo sentimentos de penúria, como a fome, são retratados poeticamente:

\footnotetext{
${ }^{11}$ VIEIRA. Rosa da farinha.

${ }^{12}$ EVARISTO. Duzu-Querença.

${ }^{13}$ Em geral, é mais comum falar-se em "romances de formação”: “A maioria dos estudiosos do Bildungsroman concorda que o que constitui o gênero é a presença de uma Bildung, a visão de mundo do protagonista, construída a partir de suas experiências e de suas reflexões sobre ela.” (SCHWANTES. Narrativas de formação contemporânea: uma questão de gênero, p. 195) Nestes termos, acreditamos que é possível estender o conceito para narrativas curtas.
} 
Duzu olhou fundo no fundo da lata, encontrando apenas o espaço vazio. Insistiu ainda. Diversas vezes levou a mão lá dentro e retornou com um imaginário alimento que jogava prazerosamente à boca. Quando se fartou deste sonho, arrotou satisfeita... ${ }^{14}$

A lembrança dos contatos com os primeiros homens também é narrada de um modo quase pueril, mediante a curiosidade juvenil que a impelia a entrar nos quartos da casa sem bater à porta, porque era “bonito”, “era bom de olhar” homens e mulheres uns sobre os outros. Até que, certa feita, num dos quartos, o homem estava deitado sozinho, e a menina se torna mulher, rápida e instintivamente aprendendo a “dançar”. Quando Dona Esmeraldina descobre, ordena que ela lhe devolva todo o dinheiro que havia ganhado. É então que se dá o processo de entendimento da personagem:

Duzu naquele momento entendeu o porquê do homem lhe dar dinheiro. Entendeu o porquê de tantas mulheres e de tantos quartos ali. Entendeu o porquê de nunca mais ter conseguido ver a sua mãe e o seu pai, e de nunca Dona Esmeraldina ter cumprido a promessa de deixá-la estudar. E entendeu também qual seria a sua vida. É, ia ficar. Ia entrar-entrando sem saber quando e por que parar. ${ }^{15}$

Contrariamente ao estereótipo da mulher sexualizada que não procria, como Vidinha, de Memórias de um sargento de milícias, a representação feminina que se dá na linhagem afrodescendente da literatura é muito centrada na figura da mãe, por vezes forte e chefe de família. Duzu dá à luz a nove filhos, que se espalham pelo mundo, pelos morros, pelos becos. E cada filho lhe dá ao menos mais dois netos, dentre os quais três eram da sua predileção. Um, no entanto, Tático, cuja “cor vermelho-sangue já se derramava em sua vida”, acaba por morrer. O motivo não é apontado textualmente, mas subentende-se que fora pelo envolvimento com a violência, ou mesmo com o tráfico, o que se infere pelo fato de o menino possuir uma arma. Nesses destinos estilhaçados, vislumbra-se o próprio destino de negros e mestiços, fruto das más condições de vida, da falta de oportunidades. Querença, a neta querida, é o elo entre o passado e o futuro, e é nesta personagem que a temática da esperança esboçada no início do conto é recapturada pela escritora. Na menina, “ancestrais e vitais sonhos haveriam de florescer e acontecer”.

Num gesto desesperado de loucura, Duzu retorna ao morro onde havia morado com os filhos, pois era preciso "ludibriar a dor". A fantasia como fuga da realidade é

\footnotetext{
${ }^{14}$ EVARISTO. Duzu-Querença.

${ }^{15}$ EVARISTO. Duzu-Querença.
} 
também poetizada na escrita de Evaristo: em tempos de carnaval, ela começa a confeccionar uma fantasia com papéis brilhantes, e, no momento de sua morte, imagens de ancestrais africanos retornam:

E foi escorregando brandamente em seus famintos sonhos que Duzu visualizou seguros plantios e fartas colheitas. (...) Faces dos ausentes retornavam. Vó Alafaia, Vô Kiliã, Tia Bambene, seu pai, sua mãe, seus filhos e netos. Menina Querença adiantava-se mais e mais. Sua imagem crescia, crescia. Duzu deslizava em visões e sonhos por um misterioso e eterno caminho... ${ }^{16}$

"Seguros plantios e fartas colheitas": Duzu entrevê um futuro melhor para sua neta, para seus descendentes negros, enfim. Quando a menina Querença fica sabendo da morte da avó, busca na memória o nome de parentes que nem havia conhecido. Aqui a memória individual cede lugar à memória coletiva, e a ancestralidade é símbolo de uma história repleta de lutas que remontam à escravidão africana, mas que podem, um dia, ser superadas:

E foi no delírio da avó (...) que ela, Querença, haveria de sempre umedecer seus sonhos para que eles florescessem e se cumprissem vivos e reais. Era preciso reinventar a vida. Encontrar novos caminhos. Não sabia ainda como. Estava estudando, ensinava as crianças menores da favela, participava do grupo de jovens da Associação de Moradores e do Grêmio da Escola. Intuía que tudo era muito pouco. A luta devia ser maior ainda. ${ }^{17}$

A luta por melhores condições de vida é ponto-chave em boa parte dos textos literários afrodescendentes. No conto “Olhos d’água” isso também está presente. Ele parte de uma indagação central que acompanha todos os movimentos da protagonista negra, narradora em primeira pessoa: “De que cor eram os olhos de minha mãe?” A figura da matriarca se impõe: a partir da pergunta anterior, a narradora-personagem rememora sua infância difícil diante das misérias por que passavam. Ainda nesse texto é o recurso ao flashback que vai possibilitar ao leitor conhecer a história das personagens. Apesar dos problemas econômicos, emerge a imagem de uma mãe que fazia de tudo para que tais sofrimentos fossem minimizados, valendo-se, mais uma vez, do artifício da fantasia para ludibriar a fome: era nos dias em que não havia nada para comer que ela mais brincava com as crianças.

\footnotetext{
${ }^{16}$ EVARISTO. Duzu-Querença.

${ }^{17}$ EVARISTO. Duzu-Querença.
} 
Para Chevalier e Gheerbrant, “o simbolismo da mãe (...) está ligado ao do mar (...), na medida em que eles são, ambos, receptáculos e matrizes da vida. O mar e a terra são símbolos do corpo materno.”18 Tal associação se faz ainda mais interessante para a leitura do conto em questão. Vejamos o trecho a seguir:

Reconhecia a importância dela na minha vida, não só dela, mas de minhas tias e todas as mulheres de minha família. E também, já naquela época, eu entoava cantos de louvor a todas as nossas ancestrais, que desde a África vinham arando a terra da vida com suas próprias mãos, palavras e sangue. Não, eu não esqueço essas senhoras, nossas Yabás, donas de tantas sabedorias. ${ }^{19}$

A linhagem ancestral e feminina é matriz, é berço cultural, é criação, é vivência, é luta, esforço que se realiza “com as próprias mãos”, e que se constrói por meio de ações (sangue) e palavras. Nos contos de Conceição Evaristo, esse traço parece ser sempre ressaltado.

Como não consegue mesmo se lembrar de que cor eram os olhos da mãe, a personagem, que havia ido embora de seu barraco - o morro também é quase sempre o cenário nos textos da escritora - e de sua cidade em busca de condições melhores de vida, resolve voltar para casa, como se cumprisse um ritual, para responder a sua inquietação. O retorno a sua cidade natal é a busca pelo resgate da própria descendência, da própria história, de sua identidade. Um deslocamento espacial que é também uma busca interior, pois ao redescobrir como eram os olhos de sua mãe, redescobria a si mesma, pois mãe e filha são como que espelhos, uma se reflete na outra, uma geração ecoa na outra:

\section{Sabem o que vi?}

Vi só lágrimas e lágrimas. (...) E só então compreendi. Minha mãe trazia, serenamente em si, águas correntezas. (...) A cor dos olhos de minha mãe era cor de olhos d’água. Águas de mamãe Oxum! Rios calmos, mas profundos e enganosos para quem contempla a vida apenas pela superfície. ${ }^{20}$

Comumente escuta-se dizer que “os olhos são a janela da alma”. Entendamos melhor este símbolo:

As metamorfoses do olhar não revelam somente quem olha; revelam também quem é olhado, tanto a si mesmo como ao observador. (...) $\mathrm{O}$

\footnotetext{
${ }^{18}$ CHEVALIER; GHEERBRANT. Dicionário de símbolos, p. 580.

${ }^{19}$ EVARISTO. Olhos d'água, p. 173-174.

${ }^{20}$ EVARISTO. Olhos d'água, p. 174.
} 
olhar aparece como símbolo e instrumento de uma revelação. Mais ainda, é um reator e um revelador recíproco de quem olha e de quem é olhado. O olhar de outrem é um espelho que reflete duas almas. ${ }^{21}$

A identificação, portanto, se dá pelo olhar. No conto em estudo, isso é ratificado ainda pelo desfecho, quando a narradora, tendo alcançado a cor dos olhos de sua mãe, tenta descobrir a cor dos olhos da filha. É esta, entretanto, quem lhe revela a chave de tudo, ao indagar: “Mãe, qual é a cor tão úmida de seus olhos?” Ou seja, a narradora tinha os olhos tais quais os da mãe, neles se reproduzia toda uma história, toda uma descendência que se perpetua de geração para geração. A água é o elemento vital; o pranto é dor, mas é também resistência. Mais ainda: a mãe tinha os olhos de mamãe Oxum que, segundo a mitologia africana, era a deusa da fertilidade na Terra, e que, um dia, reagiu contra o jugo masculino. Reza a história que quando os orixás chegaram à Terra resolveram instaurar assembleias para decidir sobre o funcionamento geral das coisas, mas as mulheres foram proibidas de participar. Oxum, furiosa com essa determinação, tornou estéreis todas as mulheres, secando as fontes de águas, e consequentemente tornando a terra improdutiva. Os orixás então se viram obrigados a convidá-la para participar das reuniões, e enfim a fecundidade foi restaurada na Terra. Vale assinalar que em “Olhos d’água” a presença masculina é nula; há uma descendência de mulheres, os pais nunca aparecem. ${ }^{22}$

Identidade que resiste aos preconceitos e ao esquecimento: pode-se afirmar que em todos os textos aqui estudados essa questão persiste. Em “Guarde segredo”, de Esmeralda Ribeiro, há uma resistência que se delineia por outros percursos. Numa releitura de Clara dos Anjos, de Lima Barreto, a autora denuncia o preconceito e a opressão a que é submetida a mulher negra, lançando um olhar crítico sobre a questão, por meio inclusive da ironia. O texto já se inicia com uma série de referentes da ordem do indeterminado, do não conhecido, criando uma atmosfera de mistério que permanece ao longo da narrativa:

Prezada Senhora:

${ }^{21}$ CHEVALIER; GHEERBRANT. Dicionário de símbolos, p. 653.

${ }^{22}$ Em "Duzu-Querença” também não há uma presença masculina forte, nem em "Guarde segredo". Em "Rosa da farinha” mencionam-se figuras masculinas fortes, mas elas ficam obrigatoriamente em segundo plano na narrativa devido à força da personagem principal. Aliás, essa é uma característica da literatura negra de autoria feminina: dos 61 contos femininos publicados em Cadernos Negros até 2008, 55 têm mulheres como protagonistas (FIGUEIREDO. A mulher negra nos Cadernos Negros, p. 17). 
Recebo com surpresa sua [de quem?] carta perguntando-me sobre vovó. Como descobriu o meu endereço? Vim para cá logo depois que presenciei aquela cena [qual?]. Aqui ninguém sabe quem sou, mas, mesmo assim, estou atordoada. [por quê?] (...) A insônia me persegue. Sabe, fatos estranhos [quais?] aconteceram enquanto morei naquela casa. [qual?] "Foi ele quem pediu pra voltar", [ele quem?] foi a última coisa que vovó disse. ${ }^{23}$

O suspense é criado porque o leitor, de imediato, mentaliza as interrogações expressas por nós entre colchetes. A partir daí, também por meio de flashback, a narradora conta sua história: por contingências da vida, se vê obrigada a morar com a avó, figura central nesta narrativa, numa casa antiga em que há um “quê” de algo fantasmagórico, como a presença de um homem que aparece e some repentinamente, e por vezes é visto a uma máquina de escrever. Mais adiante, o leitor vai percebendo a rede de intertextualidade que se constrói com o romance Clara dos Anjos: o pai da protagonista é carteiro; ela se apaixona por Cassi Jones; e o homem misterioso é o próprio Lima Barreto, transfigurado em personagem, e cuja relação com vovó Olívia é de cumplicidade.

Aliás, essa é uma avó que tudo sabe e que aparece e desaparece sem pedir licença. Mais significativo ainda: costurava uma colcha de retalhos, ponto por ponto, colcha que, no entanto, a neta jamais vira pronta. Pode-se fazer uma associação com a própria história do negro e da mulher, que é constituída paulatinamente, e em que cada movimento de resistência - cada acontecimento, cada "ponto" costurado - é um avanço, um passo além dos rígidos muros do preconceito.

O interessante nesse conto é que a releitura se dá não no plano das similitudes em relação ao conto matriz, ao contrário, o que ocorre é uma "rasura da tradição", suplementando, no sentido derridiano, o texto original. Isso porque um novo final para a história é proposto: se no primeiro conto Clara se vê seduzida e abandonada, neste ela reage à subjugação a que frequentemente a mulher negra é submetida e, ao invés de aceitar seu destino com resignação, aniquila o outro responsável pelo que seria a sua desgraça. A Clara dos Anjos de Lima Barreto era "de uma natureza amorfa, pastosa, que precisava mãos fortes que a modelassem e fixassem” e tinha "um poder reduzido de pensar”. Assim, apaixona-se e deixa-se enganar facilmente. No conto de Esmeralda Ribeiro, no entanto, lê-se: “não o amava, mas não conseguia resistir a todo aquele

\footnotetext{
${ }^{23}$ RIBEIRO. Guarde segredo, p. 163.
} 
charme”. A atração é de uma outra ordem, quase física, material, e a personagem não se deixa ludibriar emocionalmente.

Após a reação, uma espécie de segunda história, que já se delineava nas entrelinhas da narrativa, emerge de modo mais contundente:

- Você matou Cassi Jones? - ele interrompeu o meu devaneio.

- Matei - respondi. (...)

- Bravo! Esse era o outro final que eu queria para o cafajeste do Cassi Jones.

O escritor tirou da máquina o papel, rasgou em pedacinhos e jogou no lixo. Olhou para vovó e disse: "Obrigado. Eternamente obrigado." Então vovó Olívia falou aquilo: "Tinha de ser assim, minha neta”, e continuou: "Nós não devemos aceitar o destino com resignação." $(\ldots)^{24}$

Ou seja: a mulher negra, historicamente submetida ao jugo masculino, a um sistema patriarcal e, acrescente-se a isso, exposta ao preconceito de cor, não deve aceitar nenhum tipo de situação degradante passivamente; é a ideia que o conto parece transmitir a seu leitor.

Um detalhe interessante é o formato de carta sob o qual se estrutura a narrativa: se uma carta é pessoal, relativa ao campo do confidencial, a partir do momento que ao leitor é dado conhecer essa história, ela se torna pública, e o "segredo" expresso no título se torna ambíguo, pois já não há nada de secreto. Além disso, essa dicotomia expressa a dicção da mulher negra: uma constante tensão entre a necessidade do silêncio e o impulso da locução. ${ }^{25}$

Portanto, percebe-se que as palavras de Heloisa Toller se fazem pertinentes: “A escrita (da mulher) negra é construtora de pontes. Entre o passado e o presente, pois tem traduzido, atualizado e transmutado em produção cultural o saber e a experiência de mulheres através das gerações."26 Esta talvez seja a proposta central das escritoras negras: realizar um intercâmbio entre as vivências passadas e as do presente, “escrevivendo" literariamente sua história e a de seus antepassados.

\footnotetext{
${ }^{24}$ RIBEIRO. Guarde segredo, p. 168.

${ }^{25}$ MARTINS. O feminino corpo da negrura, p. 119.

${ }^{26}$ GOMES. "Visíveis e invisíveis grades": vozes de mulheres na escrita afrodescendente contemporânea.
} 


\begin{abstract}
The aim of this article is to make a few remarks on poems and short stories by contemporary black writers to demonstrate how the internal point of view of the author influences the voice of the lyrical self and of the character profiles constructed. The writers selected are Cristiane Sobral, Lia Vieira, Conceição Evaristo and Esmeralda Ribeiro. They write about an ancestral memory and social roles performed and accepted (or not) by contemporary black women.
\end{abstract}

Keywords

Literature written by women, ethnicity, contemporary writers

\title{
REFERÊNCIAS
}

CHEVALIER, Jean; GHEERBRANT, Alain. Dicionário de símbolos: mitos, sonhos, costumes, gestos, formas, figuras, cores, números. 21. ed. Rio de Janeiro: José Olympio, 2007.

EVARISTO, Conceição. Duzu-Querença. In: QUILOMBHOJE. Cadernos Negros 16. São Paulo: Edição dos Autores, 1993.

EVARISTO, Conceição. Olhos d'água. In: CONTOS DO MAR SEM FIM: antologia afro-brasileira. Rio de Janeiro: Pallas; Guiné-Bissau: Ku Si Mon; Angola: Chá de Caxinde, 2010.

FIGUEIREDO, Fernanda Rodrigues de. A mulher negra nos Cadernos Negros: autoria e representações. Dissertação (Mestrado em Letras) - Faculdade de Letras, Universidade Federal de Minas Gerais, Belo Horizonte, 2009.

GOMES, Heloisa Toller. "Visíveis e invisíveis grades”: vozes de mulheres na escrita afrodescendente contemporânea. Caderno Espaço Feminino, Uberlândia, EDUFU, v. 12, n. 15, p. 13-26, 2004. Disponível em: <http://www.letras.ufmg.br/literafro/frame.htm>.

MARTINS, Leda Maria. O feminino corpo da negrura. Revista de Estudos de Literatura, Belo Horizonte, v. 4, p. 111-121, 1996.

RIBEIRO, Esmeralda. Guarde segredo. In: CONTOS DO MAR SEM FIM: antologia afro-brasileira. Rio de Janeiro: Pallas; Guiné-Bissau: Ku Si Mon; Angola: Chá de Caxinde, 2010.

SCHWANTES, Cíntia. Narrativas de formação contemporânea: uma questão de gênero. In: DALCASTAGNÈ, Regina; LEAL, Virgínia Maria Vasconcelos. Deslocamentos de gênero na narrativa brasileira contemporânea. São Paulo: Horizonte, 2010.

SOBRAL, Cristiane. Estrangeira. In: RIBEIRO, Esmeralda; BARBOSA, Márcio. Cadernos Negros 23. São Paulo: Quilombhoje, 2000. 
SOBRAL, Cristiane. Não vou mais lavar os pratos. Brasília: Athalaia Gráfica e Editora, 2010.

VIEIRA, Lia. Meu Zumbi. In: QUILOMBHOJE. Cadernos Negros 15. São Paulo: Edição dos Autores, 1992. Disponível em: <http://www.letras.ufmg.br/literafro>.

VIEIRA, Lia. Rosa da farinha. In: QUILOMBHOJE. Cadernos Negros 22. São Paulo: Edição dos Autores, 1999. Disponível em: <http://www.letras.ufmg.br/literafro>. 